\title{
A proposed algorithm for the management of pain following spinal cord injury
}

\author{
PJ Siddall*,1 and JW Middleton ${ }^{2}$ \\ ${ }^{1}$ Pain Management Research Institute, University of Sydney, Royal North Shore Hospital, Sydney, Australia; \\ ${ }^{2}$ Rehabilitation Studies Unit, University of Sydney and Moorong Spinal Unit, Royal Rehabilitation Centre, Sydney, \\ Australia
}

\begin{abstract}
Study design: Review.
Objectives: To review published articles on the assessment, diagnosis and treatment of pain following spinal cord injury (SCI) and to synthesise evidence from these materials to formulate and propose a systematic approach to management.

Methods: Relevant articles regarding the treatment of pain were identified from electronic databases using the search terms (('spinal cord injury' or 'spinal cord injuries') and 'pain') and both ('treatment') and ('randomised controlled trials'). Relevant articles were also identified through citations in indexed journal publications and book chapters on this topic.

Results: Review of the literature indicates that there are a large variety of treatments used in the management of pain following SCI with a small number supported by strong evidence for effectiveness. A treatment algorithm is proposed based on identification of underlying pain contributors and application of appropriate treatment.

Conclusion: Although there are relatively few studies clearly indicating efficacy in this population, an algorithm for the management of pain following SCI might assist to maximise our effectiveness in the treatment of this condition. It is recognised that choice of treatment is also determined by factors such as medication availability, cost and side effects as well as the preferences and characteristics of the person being treated. Nevertheless, an algorithm is proposed as a way to synthesise our current level of knowledge, identify gaps for further study and aid in the management of this difficult problem.
\end{abstract}

Spinal Cord (2006) 44, 67-77. doi:10.1038/sj.sc.3101824; published online 23 August 2005

Keywords: spinal cord injuries; pain; treatment; neuropathic

\section{Introduction}

The effective treatment of pain following spinal cord injury (SCI) is notoriously difficult. ${ }^{1}$ Several issues hinder achieving adequate relief of pain. First, particularly with the treatment of neuropathic SCI pain, we have no treatments that can reliably produce satisfactory relief of pain even in the majority of people. ${ }^{2}$ There are few randomised controlled trials in this area. In the few that have been done, negative results outnumber positive results, leaving a very small number of pharmacological approaches that have been clearly demonstrated to have a positive therapeutic effect. ${ }^{2}$ Controlled trials of other nonpharmacological options are virtually nonexistent.

The second problem is applying the results of many studies to the clinical situation. Recent efforts have been

*Correspondence: P Siddall, Pain Management Research Institute, Royal North Shore Hospital, St Leonards, NSW 2065, Australia made to develop a consensus approach to the classification of pain following SCI, recognising that there are at least four major presentations of pain following SCI that have differing aetiologies and presumed mechanisms. ${ }^{3}$ Many early studies do not clearly identify the type of pain that is being treated, thus making it difficult to apply the results to the clinical situation with any precision.

As a result of these issues, the treatment of pain following SCI is currently far from ideal. The choice of treatment is often derived from other conditions such as peripheral neuropathic pain. In practice, a trial and error approach is followed with little to guide the clinician as to what approach should be used in which situation. Given the relative lack of information in this area, it is difficult to progress substantially beyond a trial and error approach in individual people at this stage in our knowledge. However, it may be possible to 
propose a systematic approach to treatment and management using the best current evidence available. As further evidence becomes available, it should be possible to update and modify this treatment algorithm. This process of refinement and updating will hopefully provide direction for the clinician and better outcomes for people who suffer from this debilitating problem.

\section{Methods}

To identify and synthesise information regarding the treatment of SCI pain, relevant articles were identified from the Medline (1966-2005), EMBASE (1995-2005), CINAHL (1982-2005), PsychInfo (1985-2005) and AMED (1985-2005) electronic databases. Particular focus was placed on identifying randomised controlled trials using a search strategy with the keyword and heading search terms (('spinal cord injury' or 'spinal cord injuries') and 'pain') and keyword, heading or search limit of (randomised controlled trials). To identify articles possibly missed using this search strategy, this was supplemented by a broader search using the keyword search terms (('spinal cord injury' or 'spinal cord injuries') and 'pain') combined with a keyword search on (treatment). Relevant articles were also identified through citations in indexed journal publications and book chapters on this topic.

\section{Classification of SCI pain}

Before examining treatments, consideration should be given to the classification of SCI pain. Achieving optimal relief of pain may be heavily reliant on accurate identification of the type of pain that is present. The Spinal Cord Injury Pain Task Force of the International Association of the Study of Pain has proposed a taxonomy of pain. ${ }^{3,4}$ This taxonomy proposes a tiered classification in which pain types are divided into nociceptive (musculoskeletal or visceral) and neuro- pathic (either above-level, at-level or below-level) pain types (Table 1).

Nociceptive pain occurs with stimulation of somatic or visceral nociceptors, often in association with trauma, disease or inflammation and is not usually related to a sensory or motor deficit. Although descriptors may vary, nociceptive pain is often dull, aching or stabbing in quality, with tenderness to palpation over the site of pathology. In the case of musculoskeletal pain, pain is often positional or related to activity and movement.

Neuropathic pain has been defined as pain initiated or caused by a primary lesion of dysfunction of the nervous system. ${ }^{5}$ However, the looseness of the term 'dysfunction' has led to some confusion and more recently it has been proposed that the term be confined to those conditions in which pain is initiated or caused by a primary injury to the nervous system. ${ }^{6}$ Neuropathic pain, therefore, is located in or adjacent to a region of sensory disturbance and is often associated with other sensory symptoms such as numbness and paraesthesiae. Again, descriptors are not diagnostic but neuropathic pain is often described as burning, electric and shooting. Pain often occurs in the absence of stimulation and minor stimulation, such as light touch, can lead to exaggerated pain (allodynia).

The reason for trying to make a distinction between these two types of pain is that it provides the first step in identifying a more specific type of pain such as musculoskeletal pain. It therefore provides a first step in achieving more precision in the diagnosis. In addition, treatment approaches for each type of pain are different and therefore even this broad division provides some direction for management.

\section{SCI pain types}

Musculoskeletal pain

Following SCI, acute nociceptive pain arises from damage to structures such as bones, ligaments, muscles,

Table 1 Proposed classification of pain related to SCI

\begin{tabular}{lll}
\hline Broad type (Tier 1) & Broad system (Tier 2) & Specific structures/pathology (Tier 3) \\
\hline Nociceptive & Musculoskeletal & $\begin{array}{l}\text { Bone, joint, muscle trauma or inflammation } \\
\text { Mechanical instability } \\
\text { Muscle spasm } \\
\text { Secondary overuse syndromes }\end{array}$ \\
& Visceral & $\begin{array}{l}\text { Renal calculus, bowel, sphincter dysfunction, etc. } \\
\text { Dysreflexic headache }\end{array}$ \\
& Above-level & $\begin{array}{l}\text { Compressive mononeuropathies } \\
\text { Complex regional pain syndromes }\end{array}$ \\
& At-level & $\begin{array}{l}\text { Nerve root compression (including cauda equina) } \\
\text { Syringomyelia } \\
\text { Spinal cord trauma/ischaemia (transitional zone, etc.) } \\
\end{array}$ \\
& Dual level cord and root trauma (double lesion syndrome) \\
& Below-level & Spinal cord trauma/ischaemia
\end{tabular}


intervertebral discs and facet joints. The pain is generally located in the region of preserved sensation close to the site of spinal injury although it may radiate. There is often a relationship with activity or position. Radiographs, computerised tomography (CT) scan or magnetic resonance (MR) scan may help to identify abnormal pathology, spinal alignment or instability.

Chronic musculoskeletal pain may occur with overuse or 'abnormal' use of structures such as the arm and shoulder. This type of nociceptive pain is very common in people with paraplegia and much less common in people with tetraplegia. The pain occurs in normally innervated regions rostral to the SCI level. The pain is described as aching in the area of pressure or overuse and is worse with use of involved joints or pressure on the part. Muscle spasm pain is another type of musculoskeletal pain that is commonly seen in people with incomplete injuries and usually occurs well after their injury.

\section{Visceral pain}

Pathology in visceral structures such as urinary tract infections, bowel impaction and renal calculi will generally give rise to nociceptive pain, although the level of the injury will affect the quality of the pain. Therefore, individuals with paraplegia may experience visceral pain that is identical to those who have no spinal cord damage. However, individuals with tetraplegia may experience more vague, generalised symptoms of unpleasantness that are difficult to interpret.

Visceral pain can be identified by location (abdomen) and by pain features (dull, poorly localised, bloating and cramping in nature) and may be intermittent. However, diagnosis is often difficult when sensory inputs from visceral structures are disturbed. If investigations fail to find evidence of visceral pathology, and treatments directed at visceral pathology do not relieve the pain, then consideration must be given to classifying the pain as neuropathic rather than visceral.

\section{Above-level neuropathic pain}

Neuropathic pain can occur above the level of injury and includes pains that are not specific to SCI such as complex regional pain syndromes (sometimes referred to as reflex sympathetic dystrophy, causalgia or shoulder hand syndrome) and pain due to peripheral nerve compression. Although present in the general population, people with SCI may be more susceptible to some of these pains because of the activity associated with wheelchair use or transfers. People with SCI, particularly those with cervical injuries, are at risk of developing complex regional pain syndromes affecting the upper limbs. If the pain is due to nerve compression in affected extremities, electrophysiological and MR studies can aid in diagnosis.

\section{At-level neuropathic pain}

At-level neuropathic pain refers to pain with the features typical of neuropathic pain described above and present in a segmental or dermatomal pattern within two segments above or below the level of injury. This type of pain has also been referred to as segmental, transitional zone, border zone, end zone and girdle zone pain, names that reflect its characteristic location in the dermatomes close to the level of injury. It is often associated with allodynia or hyperaesthesia of the affected dermatomes.

Neuropathic at-level pain may be due to damage to either nerve roots or the spinal cord itself. Pain arising from nerve root damage is usually unilateral and suggested by characteristics such as increased pain in relation to spinal movement. The pain may be due to direct damage to the nerve root during the initial injury or it may be secondary to spinal column instability and impingement by facet or disc material. There may be electromyographic (EMG) or somatosensory evoked potential (SSEP) abnormalities. Diagnosis is assisted by radiographic, CT or MR evidence of compression of the nerve root in the foramen by bone or disc that correlates with the location of the pain.

In the past, pain that occurs at the level of the lesion and that has features of nerve root pain has often been classified as radicular even in the absence of definitive evidence of nerve root damage. However, segmental neuropathic pain may occur in the absence of nerve root damage and may be due to spinal cord rather than nerve root pathology. Although this type of pain may be difficult to distinguish from nerve root pain on the basis of descriptors, it is important because the underlying mechanisms and therefore treatment may be different.

Syringomyelia must always be considered in the person who has delayed onset of segmental pain especially where there is a rising level of sensory loss. The loss of pain and temperature sensation is typical, but all sensory and motor functions can be affected. People describe a constant, burning pain that may be associated with allodynia or hyperalgesia. Diagnosis is established by MR scan.

An important variant of at-level neuropathic pain is seen after injury to the cauda equina. The pain is reported in the lower lumbar and sacral dermatomes and is usually described as burning, stabbing and hot. It is constant but may fluctuate with activity or autonomic activation. There are several potential aetiologies for pain after such an injury. First, the spinal cord may have lost inputs, leading to changes in central connectivity and neuronal activity that could cause pain. Second, the damaged roots of the cauda equina could be spontaneously active and generate signals that are interpreted as pain. The arachnoiditis that follows major injury to the cauda equina may limit the normal movement of the nerve roots and lead to mechanical irritation of the roots with very slight movements. Third, peripheral stimuli could lead to abnormal activity at the site of axonal injury. 


\section{Below-level neuropathic pain}

This type of pain, which is also referred to as central dysaesthesia syndrome, central pain, phantom pain or deafferentation pain, presents with spontaneous and/or evoked pain which is present often diffusely caudal to the level of SCI. It is characterised by sensations of burning, aching, stabbing or electric shocks, often with hyperalgesia and it often develops some time after the initial injury. It is constant, but may fluctuate with mood, being occupied, infections or other factors and is not related to position or movement. Sudden noises or jarring movements may trigger this type of pain. Differences in the nature of below-level neuropathic pain may be apparent between those with complete and incomplete lesions. Both complete and partial injuries may be associated with the diffuse, burning pain that appears to be associated with spinothalamic tract damage. However, incomplete injuries are more likely to have an allodynic component due to sparing of tracts conveying touch sensations.

\section{Psychological aspects of pain}

There is no doubt that psychological issues have tremendous importance in the experience and expression of pain. Persistent pain following SCI is associated with more depressive symptoms and greater perceived stress. ${ }^{7}$ There is also a strong relationship between pain, spasticity, 'abnormal nonpainful sensations' and sadness. ${ }^{8}$ Some authors have included psychological or psychogenic as a type of pain that occurs following SCI. However, applying a psychological label to the pain may be unhelpful. Rather, psychological factors should be considered as a contribution which may act to modify any of these pain types rather than considering 'psychogenic pain' as an entity in its own right. Therefore, any treatment approach needs to take into account the psychological, social and environmental factors that may be contributing to the person's experience of pain.

\section{Patient evaluation}

The assessment of every person with SCI and chronic pain requires a detailed history that describes the onset of the pain and its quality, distribution and relieving or aggravating factors. It is also important to ascertain how intervening surgeries and treatments have influenced the pain. The physical examination must precisely describe the person's neurological status. If this is changing, the relationship to the pain complaint must also be determined. The stability of the traumatised spine must be ascertained through history, physical examination and imaging studies. Electrodiagnostic studies may be useful in determining the exact levels of injury to the nervous system and specific peripheral nerve function when indicated. Diagnostic nerve blocks can also help to delineate the level of a painful lesion. On the basis of the history, physical examination and appropriate imaging and electrical studies, it should be possible to classify the pain type as described previously. The assignment of the person to one or more of these pain types will permit optimal treatment planning and implementation. As mentioned above, evaluation must include identification of psychosocial and environmental factors contributing to the problem.

\section{Toward a management algorithm}

The rest of this article will focus on the management of pain following SCI and attempt to build a management algorithm based on current available evidence. It will approach this from a clinical perspective, looking first at assessment and diagnosis and then at the treatment of identified conditions.

\section{Pain assessment}

The first step in assessment is to identify the main contributors to pain (Figure 1). In any person with pain these contributors generally fall into three broad categories: nociceptive, neuropathic and psychosocial. Psychosocial and environmental contributors include psychological and social factors such as mood, cognitions, relationships, home and workplace ergonomics and work conditions including relationships with superiors, job satisfaction and other factors. Although these factors rarely act as generators of pain, they are invariably involved in the experience of pain and need to be considered as part of the assessment of the person with pain. ${ }^{7,8}$

The next step in assessment is to attempt to identify the likely pain generators. If the pain is located in a region of preserved sensation and is described as dull and aching, then it most likely nociceptive. If the pain is located in a region of sensory disturbance and is described as shooting, electric or burning, it is most likely neuropathic.

Descriptors alone have fairly low diagnostic specificity and this division into nociceptive and neuropathic is very crude. However, it still has usefulness as a 'first pass' diagnosis and may have some limited value in choosing direction for treatment.

The next step is to identify more specifically which type of pain is present.

\section{Nociceptive pain}

If the pain appears to be nociceptive, is related to position, activities and movement and associated with somatic tenderness, then it is most likely musculoskeletal (Figure 1). If the pain appears to be nociceptive, is located in the abdomen and appears to be related to visceral function or pathology, then it is most likely visceral.

\section{Neuropathic pain}

If the pain appears to be neuropathic and is located in the region above the level of injury, it is termed above-level neuropathic pain (Figure 2). If the pain 


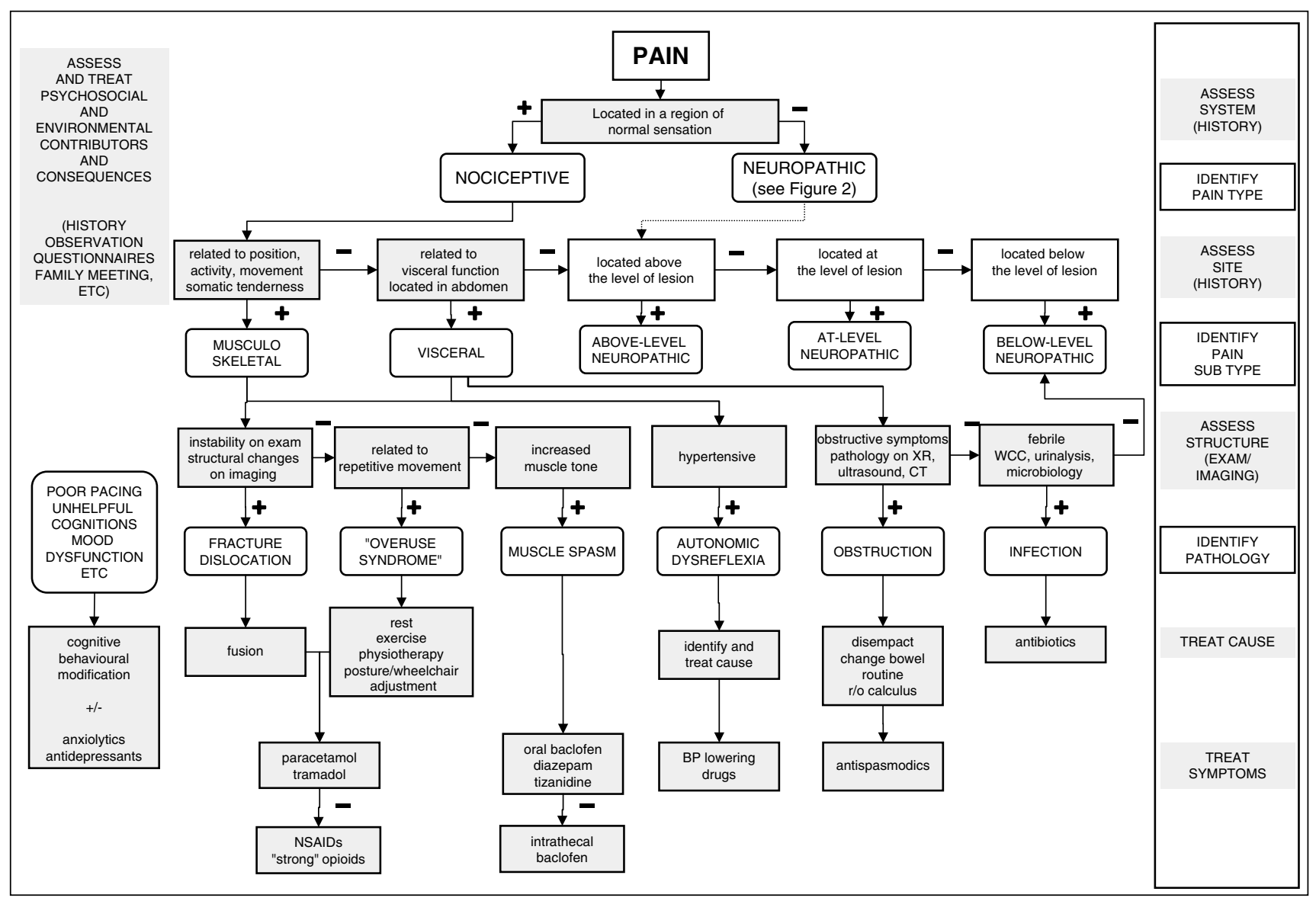

Figure 1 Assessment and treatment algorithm for the management of nociceptive pain following SCI

appears to be neuropathic and is located in the dermatomes adjacent (within two segments) to the level of injury, it is termed at-level neuropathic pain. If the pain appears to be neuropathic and is located in the region extending beyond two segments below the level of injury, it is termed below-level neuropathic pain.

The final step in assessment is to identify the structure and pathology responsible for generating the pain. It is recognised that this may be difficult if not impossible with current diagnostic techniques. However, we believe it is important to at least consider, and investigate where appropriate to determine the pathology that underlies the presence of pain.

\section{Musculoskeletal pain}

If musculoskeletal pain is present, physical examination (site of tenderness, limitation of movement, muscle tone) will help to determine the structures that may be affected and the presence of inflammation or muscle spasm (Figure 1). Particularly in the acute phase, if skeletal damage is suspected, investigations such as $\mathrm{X}$ rays, $\mathrm{CT}$ scan and MR imaging may help to identify a fracture or dislocation. In the chronic phase, restriction in range of movement of the upper limb may suggest an overuse syndrome.

\section{Visceral pain}

The presence of abdominal pain requires a standard diagnostic approach used in the assessment of anyone with suspected visceral pain. However, in the person with SCI, particular attention should be paid to conditions that are more common in this population (Figure 1). These include infection of the urinary tract and obstruction from ureteric calculi and bowel impaction. Other conditions to consider include cholelithiasis and oesophagitis. Physical examination and the appropriate tests (full blood count, electrolytes, liver function tests, urine culture) and imaging (ultrasound, X-rays, CT scan and MR imaging) or other special investigations (eg endoscopy) will help to localise the source of pain.

The onset of headache in a person with an upper thoracic or cervical SCI should alert the clinician to the possibility of a visceral disturbance such as bladder distension or bowel impaction producing autonomic dysreflexia. Inability to detect abdominal pathology in the presence of ongoing pain in a person with a high 


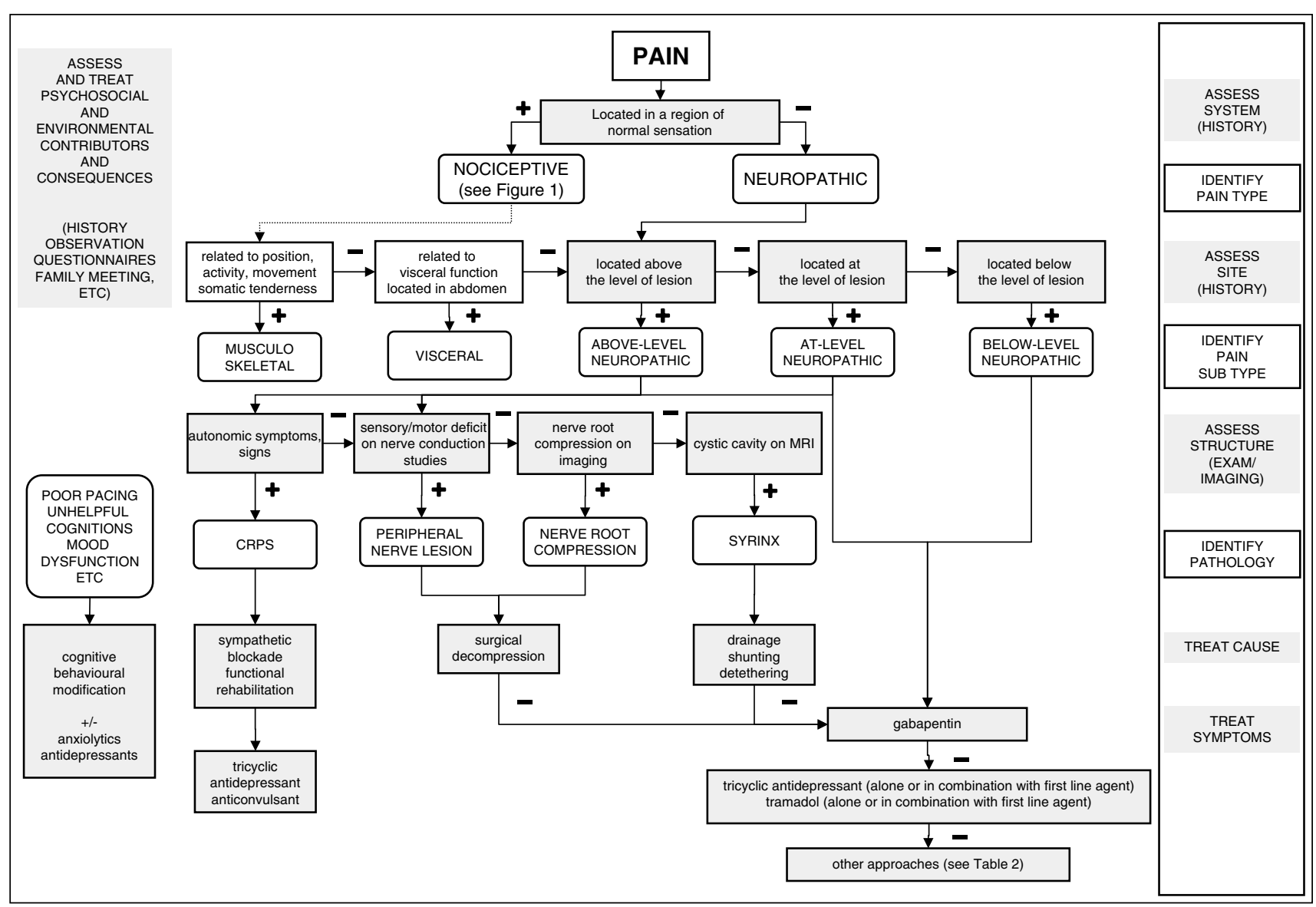

Figure 2 Assessment and treatment algorithm for the management of neuropathic pain following SCI

level spinal lesion suggests the possibility that the pain is neuropathic rather than nociceptive.

\section{Above-level neuropathic pain}

Above-level neuropathic pain may be due to a variety of pathologies (Figure 2). As they occur in the region of sensory preservation, these are often unrelated to the SCI itself, although may be more common in the spinally injured person. They include complex regional pain syndromes (sometimes referred to as shoulder-arm syndrome), nerve root compression, peripheral nerve compression and syringomyelia. Diagnosis depends on the use of physical examination to detect the nature of any sensory disturbance and the presence of other features such as autonomic dysfunction, as well as diagnostic techniques such as nerve conduction studies, CT scan and MR imaging.

\section{At-level and below-level neuropathic pain}

Further assessment of at-level and below-level neuropathic pain at this point is usually unhelpful and provides no further benefit in deciding on appropriate treatment. If there has been a recent change in the location or characteristics of the pain, MR imaging may be useful to determine the formation or progression of syringomyelia. However, apart from this, further investigation in people with this type of pain does not provide additional benefit.

\section{Psychosocial and environmental factors}

As mentioned earlier, pain and SCI can have a major psychological impact on a person. Many people with traumatic SCI also suffer neurocognitive deficits as a result of their injuries. These psychological consequences and psychosocial and environmental contributors to the experience of pain need to be identified. As well as being a cause of suffering in their own right, these factors will also influence the person's experience of pain and form a background or context in which their experience of pain occurs. Therefore, psychosocial and environmental factors need to be assessed and treated alongside and in parallel with any interventions that focus on treating physical causes of pain.

Psychosocial and environmental factors may include mood dysfunction such as depression and anxiety, maladaptive cognitions such as fear avoidance and catastrophising, and social reinforcers such as over- 
solicitous family members. This means careful observation and listening, obtaining input from family, friends and other team members and may require assistance from other professionals with formal training in psychological or psychiatric medicine.

\section{Pain treatment}

Having identified the most likely cause of the pain, the next step is to, where possible, treat the underlying cause of the pain. However, in many situations, elimination of the cause of the pain either in the short- or long-term may not be possible. The focus of treatment then becomes symptomatic relief. There are a large number of treatments that are used for symptom relief, often with little evidence of efficacy. In the case of pharmacological treatments, it is often difficult to rank treatments where efficacy is similar and other factors such as cost, availability, side effects, drug interactions and patient preference need to be considered. More invasive procedures are placed in a lower rank unless there is clear evidence that this is the preferred first-line treatment.

\section{Musculoskeletal pain}

Acute inflammatory musculoskeletal pain is largely due to direct trauma to the musculoskeletal structures and there is little that can be done to remove the cause although generally the pain will resolve as healing occurs. The identification of damage to skeletal structures that appear to be unstable requires stabilisation using external devices or internal fixation. Symptomatic treatment as described in the next section may be required to help with pain relief during healing.

Chronic inflammatory musculoskeletal pain may be due to contributing factors such as abnormal posture, gait and overuse with transfers and wheelchair use. If it is considered that these are contributing factors, then correction with education, exercise ${ }^{9}$ and retraining and/ or environmental modifications ${ }^{10}$ (eg adaptive equipment, attendant care prescription) may be sufficient to eliminate the problem. In the short term, or if it is not possible to completely address the causative factors, symptomatic treatment may also be required.

As with other situations, the symptomatic treatment of inflammatory musculoskeletal pain is largely reliant on the use of analgesics and nonsteroidal anti-inflammatory drugs (NSAIDs). Analgesic use will follow the usual stepwise approach of simple analgesics such as paracetamol (acetominophen), compound or 'weak' opioids such as codeine, dextropropoxyphene and tramadol, and 'strong' opioids such as oxycodone, morphine and methadone. Several considerations apply, however, in the person with SCI. Opioid analgesics may exacerbate bowel dysfunction as well as the usual considerations of tolerance and dependence. NSAIDs may cause gastric erosion that is more prevalent and harder to detect in those with high lesions. Therefore, we recommend the use of paracetamol as a first step followed by tramadol if there is insufficient relief. The use of NSAIDs or 'strong' opioids can be considered on a case-by-case basis if either of these drugs does not provide adequate relief of pain.

Muscle spasm may be due to underlying pathology that is maintaining a heightened reflex arc. If so, then this needs to be treated appropriately. More commonly, there is no underlying pathology that can be addressed and treatment once again focuses on symptomatic relief. Oral baclofen may be sufficient to control the symptoms and is the first-line approach. Alternatively, tizanidine or diazepam may be used but consideration must be given to the side effects associated with benzodiazepine use. Insertion of an intrathecal infusion device is invasive and is considered a second-line approach. However, there is good evidence to support the effectiveness of intrathecal baclofen administered in this way for the relief of muscle spasm where there is poor control with oral administration. ${ }^{11-13}$

\section{Visceral pain}

Identification of symptomatic urinary tract infection requires treatment with antibiotics. Obstruction from ureteric calculi may require surgical removal or lithotripsy. Bowel impaction may require disempaction in the short term and adjustment of bowel regimen/routine in the long term. The presence of autonomic dysreflexia may constitute a medical emergency and requires immediate blood pressure reduction and treatment of the triggering stimulus.

\section{Above-level neuropathic pain}

The treatment of complex regional pain syndromes is itself complex and the reader is referred to other texts that deal with this condition in more detail. ${ }^{14}$ Sympathetic blockade may provide complete relief of pain in some individuals but effectiveness is unpredictable. ${ }^{15}$ Physical rehabilitation may also be helpful in some people with complex regional pain syndromes. Nerve root or peripheral nerve compression may require surgical decompression. Syringomyelia may require drainage and shunting or a detethering procedure.

\section{At-level and below-level neuropathic pain}

Apart from treatment of a syrinx and surgical decompression of a compromised nerve root, there are no current treatments available that can treat the cause of at-level or below-level neuropathic pain. Treatments are therefore largely symptomatic. Unfortunately, there are few controlled trials that have been performed specifically examining the efficacy of treatments for the treatment of at-level and below-level neuropathic pain. Those that have been done often have small numbers and therefore conclusions may not be reliable. Treatment is therefore sometimes dependent on extrapolation from other neuropathic pain conditions.

To aid the clinician in the choice of treatment, we recommend a three-tiered approach. We recognise that 
in the absence of strong evidence that this is hazardous, different choices will be made depending on the wishes and characteristics of the person, clinician preferences, cost, availability, side effect profile and various other factors. Despite this, we also recognise that it may be helpful for clinicians to provide some practical guidelines that can be considered as a possible approach to treatment. While acknowledging the limitations of such an approach at this stage, it will hopefully provide a starting point that can be incrementally updated and clarified as evidence for specific treatments accumulates over time.

We have therefore divided treatments into three tiers based on levels of evidence. First-line treatment is based on good evidence (positive results from randomised controlled trials) specifically in the treatment of neuropathic SCI pain. Second-line treatment is based on limited, absent or even negative results from randomised controlled trials specifically in neuropathic SCI pain but good evidence from other neuropathic pain conditions. Third-line treatment is based on limited evidence in neuropathic SCI pain studies with the presence of other limiting factors such as effectiveness in specific populations, invasiveness, side effect profile and limited availability.

For both at-level and below-level neuropathic pain, we suggest that first-line treatment is systemic lignocaine, ${ }^{16-18}$ in the acute, in-patient setting and gabapen$\operatorname{tin}^{19-21}$ in the subacute or chronic setting. If gabapentin fails to provide adequate relief, we would suggest the use of a tricyclic antidepressant such as amitriptyline or nortriptyline or a weak opioid such as tramadol as a second-line treatment. Although there is limited and even negative evidence with tricyclic antidepressants alone in the treatment of SCI pain, ${ }^{22}$ there is strong evidence of efficacy in other neuropathic pain conditions ${ }^{23}$ as well as reports that combinations of anticonvulsants and tricyclic antidepressants are more effective than when either is administered alone. ${ }^{24,25}$ Therefore, if a single agent is ineffective, a combination of an anticonvulsant with either a tricyclic antidepressant or an opioid may produce additional relief. Tricyclic antidepressants should generally not be combined with tramadol because of concerns about the potential for developing serotonergic syndrome.

There are a number of third-line treatments that may be considered if the first- and second-line treatments fail. However, as evidence is limited or negative, they may be indicated for specific populations or have disadvantages that make it difficult to recommend them as first- or second-line treatments (Table 2). In the acute setting, ketamine may be an alternative to the use of lignocaine, although there is some concern about side effects such as dizziness and dysphoria. ${ }^{26,27}$ Several other agents have also been used systemically with positive results in randomised controlled trials including morphine, ${ }^{28}$ alfentanil $^{27}$ and propofol. ${ }^{29,30}$ However, as well as the invasiveness of systemic administration, effects are short term. The exception to this is a report of long-term pain relief with the use of systemic lignocaine. ${ }^{31}$ A controlled study using mexiletine found no significant advantage over placebo. ${ }^{32}$

A relatively large randomised controlled trial has been performed with the anticonvulsant pregabalin but the results are as yet unpublished. Other anticonvulsants such as sodium valproate, ${ }^{33}$ carbamazepine, ${ }^{24}$ lamotrigine, ${ }^{34}$ and topiramate ${ }^{35}$ are effective in some individuals. Topiramate has also been administered in a randomised controlled trial but numbers are small. ${ }^{36}$

Opioid analgesics such as oxycodone, methadone and morphine may provide relief but as mentioned above, side effects, tolerance and dependence are issues that need to be considered. If used, controlled release preparations provide more stable analgesia and are preferred for long-term use. Newer antidepressants such as the mixed serotonin-noradrenaline reuptake inhibitors may be effective. However, controlled studies are either nonexistent or in the case of the selective serotonin reuptake inhibitor, trazodone, indicate a lack of group effect when compared with placebo. ${ }^{37}$

Invasive procedures may also be considered as thirdline treatments. Spinal administration of drugs such as morphine ${ }^{38}$ and clonidine ${ }^{38,39}$ has been found to be effective in some individuals. A positive outcome was found with intrathecal baclofen in a randomised controlled trial ${ }^{13}$ but other reports have been less supportive. ${ }^{40}$ Combinations of morphine or clonidine with baclofen in those with spasm may confer additional benefit. ${ }^{41-42}$ In a case report and subsequent controlled study, intrathecal administration of a mixture of morphine and clonidine was found to be effective in people with chronic at-level and below-level neuropathic SCI pain. ${ }^{43,44} \mathrm{~A}$ controlled study also found a positive response to subarachnoid administration of lignocaine. ${ }^{45}$

Nonpharmacological treatments such as TENS and acupuncture may be effective for some people with neuropathic pain. ${ }^{46,47}$ Spinal cord stimulation may also provide relief, although greater effect is obtained in those with at-level neuropathic pain and incomplete lesions. $^{48}$

Other available treatments are very invasive with limited evidence of efficacy. These include deep brain stimulation $^{49,50}$ and motor cortex stimulation, ${ }^{51}$ dorsal root entry zone lesions (for at-level neuropathic pain) ${ }^{52-54}$ and surgical approaches such as cordotomy. ${ }^{55}$

\section{Psychosocial and environmental contributors}

The person with SCI undergoes a huge adjustment in relationships, lifestyle, vocation and self-image that need to be addressed and people with a severe SCI usually have significant psychological distress. ${ }^{56}$ The superimposition of chronic pain is a major factor that interferes with expected rehabilitation and return to employment and function in domestic life. ${ }^{7,57-59}$ Anxiety and depression are both normal responses to injury and often improve with time and the implementation of the person's inherent coping skills. In these people, formal intervention may not be required. However, for the 
Table 2 Evidence, limitations and specific indications of third-line treatments

\begin{tabular}{|c|c|c|c|}
\hline Treatment & Level of evidence & Disadvantages or side effects ${ }^{\mathrm{a}}$ & Specific indications \\
\hline Pregabalin & Unpublished RCT & $\begin{array}{l}\text { Somnolence, dizziness, asthenia, dry mouth, oedema, } \\
\text { constipation }\end{array}$ & \\
\hline Opioids & + ve cases & Constipation, drowsiness, tolerance, dependence & \\
\hline $\begin{array}{l}\text { Mixed serotonin/ } \\
\text { noradrenaline reuptake } \\
\text { inhibitors }\end{array}$ & + ve cases & $\begin{array}{l}\text { Hypertensive effects, gastrointestinal disturbance, dry mouth, } \\
\text { reduced appetite, sweating }\end{array}$ & \\
\hline Mexiletine & -ve RCT & $\begin{array}{l}\text { Gastrointestinal upset, cardiovascular, haematological } \\
\text { disturbance, skin reactions }\end{array}$ & \\
\hline Topiramate & + ve RCT & $\begin{array}{l}\text { Drowsiness, dizziness, ataxia, anorexia, fatigue, } \\
\text { gastrointestinal upset }\end{array}$ & \\
\hline Lamotrigine & -ve RCT & $\begin{array}{l}\text { Potentially life-threatening skin rash, hepatic effects, diplopia, } \\
\text { blurred vision, dizziness }\end{array}$ & \\
\hline Dronabinol & + ve cases & Dizziness, drowsiness, irritability & \\
\hline Older anticonvulsants & -ve RCT (valproate) & Drowsiness, dizziness, liver dysfunction, haematological effects & \\
\hline Acupuncture & + ve cases & Invasive & $\begin{array}{l}\text { Effectiveness for below-level } \\
\text { neuropathic pain uncertain }\end{array}$ \\
\hline Intravenous ketamine & + ve $\mathrm{RCT}$ & Short-term relief, invasive, dysphoria & \\
\hline Intravenous propofol & + ve RCT & $\begin{array}{l}\text { Short-term relief, invasive, hypotension, arrhythmias, } \\
\text { bradycardia }\end{array}$ & \\
\hline Intravenous alfentanil & + ve $\mathrm{RCT}$ & $\begin{array}{l}\text { Short-term relief, invasive, respiratory depression, } \\
\text { bradycardia, sedation, hypotension, nausea, vomiting }\end{array}$ & \\
\hline Intravenous morphine & + ve $\mathrm{RCT}$ & $\begin{array}{l}\text { Short-term relief, invasive, respiratory depression, sedation, } \\
\text { hypotension, nausea, vomiting }\end{array}$ & $\begin{array}{l}\text { Effectiveness demonstrated for } \\
\text { mechanical allodynia }\end{array}$ \\
\hline Intrathecal baclofen & + ve RCT & Invasive, reports of increased or 'unmasked' neuropathic pain & $\begin{array}{l}\text { Stronger evidence for spasm- } \\
\text { related pain }\end{array}$ \\
\hline $\begin{array}{l}\text { Intrathecal morphine and } \\
\text { clonidine }\end{array}$ & + ve $\mathrm{RCT}$ & $\begin{array}{l}\text { Invasive, tolerance, hypotension, respiratory depression, } \\
\text { drowsiness }\end{array}$ & \\
\hline Subarachnoid lignocaine & + ve RCT & Invasive, central nervous system disturbance & \\
\hline Spinal cord stimulation & + ve cases & Invasive & $\begin{array}{l}\text { At-level neuropathic pain, } \\
\text { incomplete injuries }\end{array}$ \\
\hline Deep brain stimulation & + ve cases & Invasive, intracranial haemorrhage & \\
\hline $\begin{array}{l}\text { Motor cortex stimulation } \\
\text { (transcranial) }\end{array}$ & + ve cases & Short-term effect & \\
\hline $\begin{array}{l}\text { Motor cortex stimulation } \\
\text { (epidural) }\end{array}$ & + ve cases & Invasive & \\
\hline DREZ & + ve cases & Invasive, risk of further deficits & At-level neuropathic pain \\
\hline Cordotomy & + ve cases & Invasive, risk of further deficits & \\
\hline
\end{tabular}


minority who experience severe or chronic mood dysfunction that is having an impact on their ability to function and contributing to pain, intervention should be offered. There are a variety of approaches for dealing with psychosocial and environmental contributors. These may include the use of anxiolytic and antidepressant medications and/or cognitive behavioural treatment. ${ }^{60}$ It has also been demonstrated that exercise may be of benefit in improving pain and mood. ${ }^{61}$ In addition, it may be necessary to address other external factors that are believed to be contributing to the pain.

\section{Conclusion}

There are currently few treatments that have clearly demonstrated efficacy, particularly in the treatment of neuropathic SCI pain. We propose this algorithm as a suggested approach to the diagnosis and treatment of pain following SCI based on currently available evidence. Further debate and the addition of new knowledge of mechanisms and treatment will hopefully lead to the development of systematic treatment guidelines that provide the best outcomes for people with pain following SCI.

\section{Acknowledgements}

We thank Associate Professor Michael Nicholas, Dr Sue Rutkowski, Ms Kathryn Nicholson Perry, Ms Lois Tonkin and Ms Annalisa Dezarnaulds for their helpful insights and comments during the preparation of this review.

\section{References}

1 Yezierski RP. Pain following spinal cord injury: the clinical problem and experimental studies. Pain 1996; 68: 185-194.

2 Finnerup NB et al. Pharmacological treatment of spinal cord injury pain. In: Burchiel KJ, Yezierski RP (eds.). Spinal Cord Injury Pain: Assessment, Mechanisms, Management. Progress in Pain Research and Management. Vol. 23. IASP Press: Seattle 2002, pp 341-351.

3 Siddall PJ, Yezierski RP, Loeser JD. Taxonomy and epidemiology of spinal cord injury pain. In: Burchiel KJ, Yezierski RP (eds.). Spinal Cord Injury Pain: Assessment, Mechanisms, Management. Progress in Pain Research and Management. Vol. 23. IASP Press: Seattle 2002, pp 9-24.

4 Siddall PJ, Yezierski RP, Loeser JD. Pain following spinal cord injury: clinical features, prevalence, and taxonomy. Int Assoc Study Pain Newslett 2000; 3: 3-7.

5 Merskey H, Bogduk N. Classification of Chronic Pain: Descriptions of Chronic Pain Syndromes and Definitions of Pain Terms. IASP Press: Seattle 1994.

6 Max MB. Clarifying the definition of neuropathic pain. Pain 2002; 96: 406-407.

7 Rintala D, Loubser PG, Castro J, Hart KA, Fuhrer MJ. Chronic pain in a community-based sample of men with spinal cord injury: prevalence, severity, and relationship with impairment, disability, handicap, and subjective wellbeing. Arch Phys Med Rehabil 1999; 79: 604-614.

8 Widerström-Noga EG, Felipe-Cuervo E, Broton JG, Duncan RC, Yezierski RP. Perceived difficulty in dealing with consequences of spinal cord injury. Arch Phys Med Rehabil 1999; 80: 580-586.

9 Hicks AL et al. Long-term exercise training in persons with spinal cord injury: effects on strength, arm ergometry performance and psychological well-being. Spinal Cord 2005; 41: 34-43.

10 Crowe J, MacKay-Lyons M, Morris H. A multi-centre, randomized controlled trial of the effectiveness of positioning on quadriplegic shoulder pain. Physiother Can 2005; 52: 266-273.

11 Penn RD, Kroin JS. Long-term intrathecal baclofen infusion for treatment of spasticity. J Neurosurg 1987; 66: 181-185.

12 Lewis KS, Mueller WM. Intrathecal baclofen for severe spasticity secondary to spinal cord injury. Ann Pharmacother 1993; 27: 767-774.

13 Herman RM, D'Luzansky SC, Ippolito R. Intrathecal baclofen suppresses central pain in patients with spinal lesions: a pilot study. Clin J Pain 1992; 8: 338-345.

14 Wasner G, Schattschneider J, Binder A, Baron R. Complex regional pain syndrome - diagnostic, mechanisms, CNS involvement and therapy. Spinal Cord 2003; 41: 61-75.

15 Kingery WS. A critical review of controlled clinical trials for peripheral neuropathic pain and complex regional pain syndromes. Pain 1997; 73: 123-139.

16 Attal $\mathrm{N}$ et al. Intravenous lidocaine in central pain: a double-blind, placebo-controlled, psychophysical study. Neurology 2000; 54: 564-574.

17 Backonja M, Gombar KA. Response of central pain syndromes to intravenous lidocaine. J Pain Symptom Manag 1992; 7: 172-178.

18 Finnerup NB et al. Intravenous lidocaine relieves spinal cord injury pain: a randomized controlled trial. Anesthesiology 2005; 102: 1023-1030.

19 To TP et al. Gabapentin for neuropathic pain following spinal cord injury. Spinal Cord 2002; 40: 282-285.

20 Tai Q, Kirshblum S, Chen B, Millis S, Johnston M, DeLisa JA. Gabapentin in the treatment of neuropathic pain after spinal cord injury: a prospective, randomized, doubleblind, crossover trial. J Spinal Cord Med 2002; 25: 100-105.

21 Levendoglu F, Ogun CO, Ozerbil O, Ogun TC, Ugurlu H. Gabapentin is a first line drug for the treatment of neuropathic pain in spinal cord injury. Spine 2004; 29: 743-751.

22 Cardenas DD, Warms CA, Turner JA, Marshall H, Brooke MM, Loeser JD. Efficacy of amitriptyline for relief of pain in spinal cord injury: results of a randomized controlled trial. Pain 2002; 96: 365-373.

23 Sindrup SH, Jensen TS. Efficacy of pharmacological treatments of neuropathic pain: an update and effect related to mechanism of drug action. Pain 1999; 83: 389-400.

24 Sandford PR, Lindblom LB, Haddox JD. Amitriptyline and carbamazepine in the treatment of dysesthetic pain in spinal cord injury. Arch Phys Med Rehabil 1992; 73: 300-301.

25 Erzurumlu A, Dursun H, Gunduz S. The management of chronic pain in spinal cord injured patients. The comparison of effectiveness of amitriptyline and carbamazepine combination and electroacupuncture application. J Rheumatol Med Rehabil 1996; 7: 176-180.

26 Kvärnstrom A, Karlsten R, Quiding H, Gordh T. The analgesic effect of intravenous ketamine and lidocaine on pain after spinal cord injury. Acta Anaesthesiol Scand 2004; 48: 498-506.

27 Eide PK, Stubhaug A, Stenehjem AE. Central dysesthesia pain after traumatic spinal cord injury is dependent on 
$N$-methyl-D-aspartate receptor activation. Neurosurgery 1995; 37: 1080-1087.

28 Attal N, Guirimand F, Brasseur L, Gaude V, Chauvin M, Bouhassira D. Effects of IV morphine in central pain - a randomized placebo-controlled study. Neurology 2002; 58: 554-563.

29 Canavero S et al. Propofol analgesia in central pain - preliminary clinical observations. J Neurol 1995; 242: 561-567.

30 Canavero S, Bonicalzi V. Intravenous subhypnotic propofol in central pain: a double-blind, placebo-controlled, crossover study. Clin Neuropharmacol 2004; 27: 182-186.

31 Cahana A, Carota A, Montadon ML, Annoni JM. The long-term effect of repeated intravenous lidocaine on central pain and possible correlation in positron emission tomography measurements. Anesth Analg 2004; 98: 1581-1584.

32 Chiou Tan FY, Tuel SM, Johnson JC, Priebe MM, Hirsh DD, Strayer JR. Effect of mexiletine on spinal cord injury dysesthetic pain. Am J Phys Med Rehabil 1996; 75: 84-87.

33 Drewes AM, Andreasen A, Poulsen LH. Valproate for treatment of chronic central pain after spinal cord injury. A double-blind cross-over study. Paraplegia 1994; 32: 565-569.

34 Finnerup NB, Sindrup SH, Flemming WB, Johannesen IL, Jensen TS. Lamotrigine in spinal cord injury pain: a randomized controlled trial. Pain 2002; 96: 375-383.

35 Dinoff BL, Richards JS, Ness TJ. Use of topiramate for spinal cord injury-related pain. J Spinal Cord Med 2003; 26: $401-403$.

36 Harden RN et al. Topiramate in the management of spinal cord injury pain: a double-blind, randomized, placebocontrolled pilot study. In: Yezierski RP, Burchiel KJ (eds.). Spinal Cord Injury Pain: Assessment, Mechanisms, Management. Progress in Pain Research and Management. Vol. 23. IASP Press: Seattle 2002, pp 393-407.

37 Davidoff G, Guarracini M, Roth E, Sliwa J, Yarkony G. Trazodone hydrochloride in the treatment of dysesthetic pain in traumatic myelopathy: a randomized, double-blind, placebo-controlled study. Pain 1987; 29: 151-161.

38 Glynn C, Dawson D, Sanders R. A double-blind comparison between epidural morphine and epidural clonidine in patients with chronic non-cancer pain. Pain 1988; 34: 123-128.

39 Glynn CJ, Jamous MA, Teddy PJ, Moore RA, Lloyd JW. Role of spinal noradrenergic system in transmission of pain in patients with spinal cord injury. Lancet 1986; ii: 1249-1250.

40 Loubser PG, Akman NM. Effects of intrathecal baclofen on chronic spinal cord injury pain. J Pain Symptom Manag 1996; 12: 241-247.

41 Middleton JW, Siddall PJ, Walker S, Molloy AR, Rutkowski SB. Intrathecal clonidine and baclofen in the management of spasticity and neuropathic pain following spinal cord injury: a case study. Arch Phys Med Rehabil 1996; 77: 824-826.

42 Gatscher S, Becker R, Uhle E, Bertalanffy H. Combined intrathecal baclofen and morphine infusion for the treatment of spasticity related pain and central deafferentation pain. Funct Rehabil Neurosurg Neurotraumatol 2002; 79: 75-76.

43 Siddall PJ, Gray M, Rutkowski S, Cousins MJ. Intrathecal morphine and clonidine in the management of spinal cord injury pain: a case report. Pain 1994; 59: 147-148.
44 Siddall PJ, Molloy AR, Walker S, Mather LE, Rutkowski SB, Cousins MJ. Efficacy of intrathecal morphine and clonidine in the treatment of neuropathic pain following spinal cord injury. Anesth Analg 2000; 91: 1493-1498.

45 Loubser PG, Donovan WH. Diagnostic spinal anaesthesia in chronic spinal cord injury pain. Paraplegia 1991; 29: $25-36$.

46 Norrbrink Budh C, Lundeberg T. Non-pharmacological pain-relieving therapies in individuals with spinal cord injury: a patient perspective. Complement Ther Med 2004; 12: 189-197.

47 Rapson LM, Wells N, Pepper J, Majid N, Boon H. Acupuncture as a promising treatment for below-level central neuropathic pain: a retrospective study. J Spinal Cord Med 2003; 26: 21-26.

48 Cioni B, Meglio M, Pentimalli L, Visocchi M. Spinal cord stimulation in the treatment of paraplegic pain. J Neurosurg 1995; 82: 35-39.

49 Hosobuchi Y. Subcortical electrical stimulation for control of intractable pain in humans: report of 122 cases. J Neurosurg 1986; 64: 543-553.

50 Kumar K, Toth C, Nath RK. Deep brain stimulation for intractable pain: a 15 year experience. Neurosurgery 1997; 40: $736-746$.

51 Nguyen J-P et al. Chronic motor cortex stimulation in the treatment of central and neuropathic pain. Correlations between clinical, electrophysiological and anatomical data. Pain 1999; 82: 245-251.

52 Edgar RE, Best LG, Quail PA, Obert AD. Computerassisted DREZ microcoagulation: posttraumatic spinal deafferentation pain. J Spinal Disord 1993; 6: 48-56.

53 Nashold Jr BS, Bullitt E. Dorsal root entry zone lesions to control central pain in paraplegics. J Neurosurg 1981; 55: 414-419.

54 Sindou M, Mertens P, Wael M. Microsurgical DREZotomy for pain due to spinal cord and/or cauda equina injuries: long-term results in a series of 44 patients. Pain 2001; 92: 159-171.

55 Tasker RR, DeCarvalho GTC, Dolan EJ. Intractable pain of spinal cord origin: clinical features and implications for surgery. J Neurosurg 1992; 77: 373-378.

56 Summers JD, Rapoff MA, Varghese G, Porter K, Palmer RE. Psychosocial factors in chronic spinal cord injury pain. Pain 1991; 47: 183-189.

57 Lundqvist C, Siosteen A, Blomstrand C, Lind B, Sullivan M. Spinal cord injuries: clinical, functional, and emotional status. Spine 1991; 16: 78-83.

58 Westgren N, Levi R. Quality of life and traumatic spinal cord injury. Arch Phys Med Rehabil 1998; 79: 1433-1439.

59 Widerström-Noga EG, Duncan R, Felipe-Cuervo E, Turk DC. Assessment of the impact of pain and impairments associated with spinal cord injuries. Arch Phys Med Rehabil 2002; 83: 395-404.

60 Craig AR, Hancock K, Dickson H, Chang E. Long-term psychological outcomes in spinal cord injured persons: results of a controlled trial using cognitive behaviour therapy. Arch Phys Med Rehabil 1997; 78: 33-38.

61 Martin Ginis KA et al. Using exercise to enhance subjective well-being among people with spinal cord injury: the mediating influences of stress and pain. Rehabil Psychol 2003; 48: 157-164. 